\title{
Recruitment-dance signals draw larger audiences when honey bee colonies have multiple patrilines
}

\author{
M. B. Girard • H. R. Mattila • T. D. Seeley
}

Received: 22 June 2010/Revised: 19 August 2010/ Accepted: 24 August 2010/Published online: 17 September 2010

(C) The Author(s) 2010. This article is published with open access at Springerlink.com

\begin{abstract}
Honey bee queens (Apis mellifera) who mate with multiple males produce colonies that are filled with numerous genetically distinct patrilines of workers. A genetically diverse colony benefits from an enhanced foraging effort, fuelled in part by an increase in the number of recruitment signals that are produced by foragers. However, the influence of patriline diversity on the attention paid to these signals by audiences of potentially receptive workers remains unexplored. To determine whether recruitment dances performed by foragers in multiple-patriline colonies attract a greater number of dance followers than dances in colonies that lack patriline diversity, we trained workers from multiple- and singlepatriline colonies to forage in a greenhouse and monitored their dance-following activity back in the hives. On average, more workers followed a dance if it was performed in a multiple-patriline colony rather than a single-patriline colony (33\% increase), and for a greater number of dance circuits per follower. Furthermore, dance-following workers in multiple-patriline colonies were more likely to exit their hive after following a dance, although this did not translate to a difference in colony-level exit rates between treatment types. Recruiting nest mates to profitable food sources through dance communication is critical to a colony's foraging
\end{abstract}

M. B. Girard ( $₫)$

Department of Environmental Science,

Policy and Management, University of California,

Berkeley, 137 Mulford Hall, Berkeley, CA 94720, USA

e-mail: maddiegirard34@berkeley.edu

H. R. Mattila

Department of Biological Sciences,

Wellesley College, Wellesley, MA 02481, USA

T. D. Seeley

Department of Neurobiology and Behavior,

Cornell University, Ithaca, NY 14853, USA success and long-term fitness; polyandrous queens produce colonies that benefit not only from increased recruitment signalling, but also from the generation of larger and more attentive audiences of signal receivers. This study highlights the importance of integrating responses of both signal senders and receivers to understand more fully the success of animal-communication systems.

Keywords Animal communication - Apis mellifera . Genetic diversity $\cdot$ Recruitment signalling ·

Waggle-dance language

\section{Introduction}

Eusocial insect taxa in the Order Hymenoptera are characterized by work forces of non-reproductive individuals who share high levels of intracolonial relatedness (Wilson, 1971). Typically, close relatedness among colony members is maintained through monandry (Strassmann, 2001), when a queen mates with a single male. Monandry is ancestral in the Hymenoptera and remains widespread across the majority of its extant social species (Hughes et al., 2008a). Because of the haplodiploid system of sex determination, a monandrous queen produces a work force of female offspring who have on average $75 \%$ of their genes in common, a condition that is viewed as an important precursor for the repeated evolution of altruism in hymenopteran societies (Hughes et al., 2008a).

However, not all eusocial Hymenoptera have work forces that are populated by highly related kin. Colonies of a minority of species of social bees, ants and wasps are comprised of genetically distinct patrilines of workers because the queens that head them have each mated with multiple males (polyandry). Extremely polyandrous mating behav- 
iour has evolved repeatedly in eusocial groups such as the army and driver ants (Eciton, Dorylus; Kronauer et al., 2004, 2006), leaf-cutter ants (Atta, Acromyrmex; Villesen et al., 2002), harvester ants (Pogonomyrmex; Wiernasz et al., 2004), yellow jacket wasps (Vespula; Foster and Ratnieks, 2001) and honey bees (Apis; Oldroyd and Wongsiri, 2006; Palmer and Oldroyd, 2000; Tarpy et al., 2004). Thus, extreme polyandry presents a fascinating challenge to the predicted scenario of high levels of intracolonial relatedness in eusocial hymenopteran colonies. Polyandry in honey bees is particularly intriguing in contrast to the ancestral state of monandry in the Hymenoptera because, across species, it occurs universally and to a tremendous extent. Queens of the European honey bee (Apis mellifera) typically mate with an average of 12 different males (drones) (Tarpy et al., 2004), with a record of 44 mates reported for one queen (Moritz et al., 1996). One A. dorsata colony was found to have a staggering 102 patrilines (Wattanachaiyingcharoen et al., 2003). Such exceptionally promiscuous honey bee queens create work forces that are so genetically diverse that within-colony relatedness is diminished to a degree seemingly at odds with the promotion of altruism based on inclusive-fitness benefits (Hamilton, 1964). However, honey bee workers have lost full reproductive totipotency and the option to gain significant direct fitness, which forces them to act as helpers and accept reductions in indirect fitness should queens mate multiply and levels of within-colony relatedness decline (Beekman et al., 2006).

That extreme polyandry is so pervasive in Apis suggests that it is favoured strongly by selection once workers are locked into a non-reproductive role (Boomsma, 2009; Brown, 2003; Crozier and Fjerdingstad, 2001; Crozier and Page, 1985; Hughes et al., 2008a, b; Oldroyd and Fewell, 2008). Indeed, a growing body of evidence shows that honey bee colonies reap numerous fitness benefits from the genetic diversity that is introduced into their population by the polyandrous behaviour of their queens. Honey bee queens who mate multiply minimize the fitness load incurred by colonies as a result of the production of sterile diploid males (Page, 1980; Shaskolsky, 1976; Tarpy and Page, 2002) and produce work forces with an enhanced ability to overcome the effects of parasites and pathogens (Baer and Schmid-Hempel, 2001; Palmer and Oldroyd, 2003; Seeley and Tarpy, 2007; Sherman et al., 1988; Tarpy and Seeley, 2006). Importantly, intracolonial genetic diversity has been linked to an increase in colony-level productivity and long-term fitness (Fuchs and Schade, 1994; Jones et al., 2004; Oldroyd et al., 1992; Mattila and Seeley, 2007). Similar increases in colony growth and foraging productivity have been found in harvester ants (Cole and Wiernasz, 1999; Wiernasz et al., 2004, 2008) and wasps (Goodisman et al., 2007) as mate number per queen rises.
For honey bees, colony productivity is boosted in part by an enhanced use of recruitment communication in genetically diverse, multiple-patriline colonies compared with those that lack the same degree of diversity because they have monandrous queens and single patrilines (Mattila et al., 2008; Mattila and Seeley, 2010). Honey bees use elaborate signals, such as the waggle dance and shaking signal, to communicate to nest mates information about the availability and location of profitable food resources (Seeley, 1995; von Frisch, 1967). Given the same foraging environment, workers in multiple-patriline colonies, as a collective, produce longer and more frequent waggle-dance signals; they advertise food resources that are farther away from the nest, and they produce more shaking signals at the start of the day of foraging than do workers in single-patriline colonies (Mattila et al., 2008). Foragers in genetically diverse colonies show universally a heightened responsiveness to available resources, including colony-wide decreases in dance-response thresholds (i.e., across all patrilines) and increases in per capita rate of resource visitation and duration of dance response relative to colonies with minimal diversity (Mattila and Seeley, 2010). Taken together, these studies highlight some of the mechanisms by which greater signal output contributes to increases in the foraging effort of colonies with polyandrous queens.

Mattila and Seeley (2010) focused on the recruitment signals that are produced by honey bee foragers in multipleand single-patriline colonies without considering the other half of the equation - the effect of these signals on their intended audience. Recruitment can be enhanced not only by the production of stronger signals by senders, but also by an increase in the number of receivers who heed signals and subsequently respond to the information that they contain. By examining the response of honey bee workers to the dances that they follow, the effects of increased signal production by dancers can be integrated with the response of the workers that follow those dances to more completely understand how a colony's foraging and recruitment effort benefits from genetic diversity within its work force. Hence, the aim of this study was to compare the behaviour of workers as they attend dances that are performed by foragers in multiple-patriline colonies to that of workers exposed to signals in single-patriline colonies. We trained workers from both types of colonies to forage in a greenhouse where a single feeder contained known concentrations of sucrose solution and, as the foragers danced to advertise the food source back in their hive, we determined (1) the number of workers that followed a dance, (2) the number of dance circuits that were followed per dance follower, (3) the action taken by followers after they stopped attending a dance, and (4) the rate at which workers exited the hive as recruitment to the feeder began. Using these data, we assess how differences in foraging performance can arise between genetically 
diverse and uniform colonies from the perspective of those individuals who are motivated to seek out and to act on the recruitment signals that are available to them in their colonies.

\section{Methods}

Creating multiple-patriline and single-patriline colonies

Multiple-patriline and single-patriline colonies were created by introducing into five-frame host colonies queens that had been instrumentally inseminated with semen from differing numbers of drones. Queens destined to head single-patriline colonies were inseminated with semen from a single drone; queens that would lead multiple-patriline colonies were inseminated with semen from 14 to 15 drones (based on paternity analysis of samples of workers collected from each colony; see Mattila and Seeley, 2010). Regardless of the number of contributing drones, an equal volume of semen $(1 \mu \mathrm{L})$ was used to inseminate each queen. Each queen's semen or semen mixture was unique in content because a drone was not used to inseminate more than one queen; consequently, a drone's patriline was represented only once among the experimental colonies. Drones used in the inseminations were selected randomly from a pool of approximately 1,000 sexually mature drones that were pulled from 23 drone-source colonies, including Carniolan, Minnesota Hygenic Italian, Cordovan Italian, Russian and Varroa-Sensitive Hygenic strains that were maintained by a queen breeder (Glenn Apiaries, Fallbrook, California; as described by Mattila and Seeley, 2010). The inseminated queens were daughters of a single Carniolan queen mated to only one Carniolan drone and, thus, were as highly related as possible $(r=0.75)$.

The queens were reared and inseminated in early spring 2007 and subsequently shipped to Ithaca, NY, where they were introduced into host colonies at Cornell University's Liddell Field Station on 1 May 2007. Thereafter, colonies were inspected weekly to ensure that the inseminated queens were present and ovipositing well. To limit the effects of compromised health on worker behaviour, colonies were also medicated to protect against varroatosis and American/ European foulbrood (see Mattila and Seeley, 2010, for further details). A colony was eliminated from the study if its queen laid eggs in a spotty pattern or if symptoms of an untreatable disease were evident (e.g. chalkbrood). Data collection did not begin until 8 weeks after the inseminated queens were introduced into colonies, which allowed time for the natural turnover of each host colony's worker population with that of their new queen. From a group of 20 healthy colonies, a total of six colonies were chosen randomly for the study, of which three were multiple-patriline and three were single-patriline colonies. In each colony, the behaviour of potential recruits was explored as their colony's foragers advertised the availability of a profitable food source with recruitment dances.

Getting foragers to dance for a controlled food source

We examined the behaviour of the audience of workers who followed dances that were performed by foragers trained to visit a feeder in a greenhouse as part of a separate study (i.e. for the purpose of assaying the latter group's foraging and dancing behaviour, see Mattila and Seeley, 2010). We studied the colonies one at a time, alternating between multiple-patriline and single-patriline treatment groups. For each colony, the queen and approximately 4,000 workers were transferred into a two-frame observation hive. The bottom frame contained mostly eggs, larvae, pupae, and limited food stores; the top frame was empty honeycomb. The observation hive was consistently assembled in this manner to generate a strong colony with virtually no reserves of food whose workers would be eager to make use of any food source that we provided.

Once a colony was installed in the observation hive, it was moved into a greenhouse $\left(5 \times 6.5 \mathrm{~m}^{2}\right)$ at Liddell where it was left undisturbed for at least $24 \mathrm{~h}$, during which time the bees had a chance to become familiar with the greenhouse environment and to orient to their new hive entrance (i.e., after this period, almost all foragers who explored the greenhouse returned back the observation hive). A source of water was available to the colony at all times, but foragers did not have access to external sources of food outside of the periods during which the feeder was stocked and the behaviour of recruiting foragers and dance-following workers was monitored (see below).

After the colony's workers had adjusted to their new surroundings, a group of 15-30 workers was trained in the early morning (07:00-09:00) to visit a feeder that held $1.5 \mathrm{M}$ anise-scented sucrose solution, according to methods described by Seeley (1995). Any worker who visited the feeder during the training period was marked with paint; thus, workers that had not yet been to the feeder were identifiable because they lacked a mark. After training was over, the feeder was removed, the foragers returned to the hive and the colony became relatively inactive. An hour later, the feeder was reopened and stocked with increasingly concentrated solutions of anise-scented sucrose $(0.5,1.0$, $1.5,2.0,2.5 \mathrm{M}$ ) for $30 \mathrm{~min}$ per concentration (hereafter referred to as a "trial"), but was then removed for a 1-h interval between each trial to allow the forager work force to return to the hive and become quiescent. The behaviour of the trained foragers was assayed daily over a 5-day period in our companion study (Mattila and Seeley, 2010); but for this analysis, we examined the behaviour of potential recruits as 
they followed the dances of the trained foragers on only the first day of the assay, when the colony's population had no prior experience with the feeder.

When the feeder was stocked, the trained foragers visited the feeder and some of them danced when they returned to the hive. We were interested in examining the response of potential recruits to dance signals that were produced at the low and high end of the spectrum of concentrations that were available to the colony. Workers performed few recruitment dances when the feeder was stocked with $0.5 \mathrm{M}$ sucrose (Mattila and Seeley, 2010). Therefore, 1.0 M sucrose was the lowest concentration of sucrose for which dance-following behaviour was examined and these observations were compared with dance-following behaviour of potential recruits when the feeder was stocked with $2.0 \mathrm{M}$ sucrose solution. There was only one intervening concentration during which time dance followers would have had an additional opportunity to get recruited to the feeder.

Each time the feeder was stocked with sucrose solution, we videotaped (Sony, DCR-HC90) the observation hive's entrance and dance floor, that is, the area of comb adjacent to the entrance where foragers have the greatest probability of advertising a food source. The design of the observation hive forced workers to enter and exit the hive and dance on only one side of the bottom comb; thus, the video camera captured all of focal dances and the activity of potential recruits as they moved about the dance floor or if they left the hive. One of us (M.B.G.) was stationed at the observation hive and identified dancers by their paint mark so that specific individuals could be easily distinguished during analysis of the video. A second observer (H.R.M.) monitored the stocked feeder and collected all unmarked recruits as soon as they landed on the feeder; captured recruits were held in a screened cage throughout the remainder of the trial. This action prevented the recruits from getting experience with the food reward and guaranteed that a dance follower who was observed during a 30-min trial had not yet been to the feeder during that trial. The recruits were released after the feeder was emptied at the end of each trial, so it is possible that the same unmarked dance follower's behaviour was analysed during trials for both the 1.0 and $2.0 \mathrm{M}$ sucrose solutions.

\section{Observing the behaviour of dance followers}

Videotapes of the observation hive's dance floor and entrance were analyzed, blind to patriline treatment, using a digital-video editor (Sony DSR-30), which allowed us to resolve the timing of the movement of focal dancers and dance followers to $1 / 30 \mathrm{~s}$. For our study, a dance follower was defined according to Wray et al. (2008) as a worker who was within one bee length of a dancer with her head oriented towards the dance. As an additional requirement, our dance followers had to be clearly following a focal dancer's circuits as she moved. Individuals who were temporarily pushed farther away from the focal dancer by the movements of other bees were regarded as continuous followers only if it was obvious that they were adjusting their position to increase their proximity to the dancer. A worker was considered to have finished following a dance if, after 2-s of having been clearly attending a dance, she did not regain her position within one bee length away from the focal dancer. If a dance follower stopped following a focal dance but started to follow it again before the end of the observation interval (defined below), the number of circuits followed was summed, as was duration of following.

In order to gather data on the activity of dance followers, it was first necessary to choose focal dances. Ideally, we sought to identify in each colony up to ten dances that were performed by ten different paint-marked workers during the first 15 min of each 30-min trial. By selecting dances based on these criteria, (1) we attempted to keep consistent across colonies any potential variability in dance following that was linked to the nature of the focal dance by sampling as many focal dances as possible, and (2) we consistently limited our analysis of dance-following behaviour to the early stages of recruitment, when naive foragers should depend most heavily on signals that are produced by knowledgeable nest mates. However, sometimes it was not possible to find ten dances performed by ten unique dancers during the first half of a trial and a dancer had to be used more than once as a source of a dance (overall, an average of $63 \%$ of dances were performed by different dancers within a trial). Additionally, we tried to choose focal dances where the dancer executed at least ten continuous circuits upon re-entering the hive. We wanted to avoid shorter dances to ensure that workers had ample opportunity to follow a focal dance before it ended; otherwise, differences in dance following between treatments might have been artificially underestimated. Dancers who foraged in the greenhouse performed "round" waggle dances with brief waggling phases that indicated the close proximity of the feeder to the hive (Kirchner et al., 1988; Jensen et al., 1997; Gardner et al., 2007); thus a dance circuit was counted as each time a dancer rounded the top of her circular path. Mean number of circuits in each focal dance and the length of time that it took for each dancer to complete those circuits were estimated for the entire dance (from start to finish) so that we could determine whether there was a difference in the duration or tempo of the focal dances between multiplepatriline and single-patriline colonies.

Based on these definitions of a focal dance and a dance follower, we counted the number of workers that followed at least one circuit of the first ten circuits of each focal dance. By examining the number of workers that oriented to and followed some part of the first ten circuits that were exe- 
cuted by a dancer, we ensured that nearby workers had similar opportunity across focal dances to notice and respond to a dance without being influenced by a crowd of followers that might already be in attendance at a long-running dance. After counting the number of workers that followed some part of the first ten circuits of a dance, we selected the first three workers who oriented to that dance (or fewer if no more attended the dance) and then we measured the number of circuits that each of these individual dance followers followed once the dance began (including beyond the first ten circuits of the dance, if they followed that long). Most of our focal dance followers abandoned the focal dance before it was over; only $8.5 \%$ of all dance followers were forced to end prematurely their dancing following, that is, the dance ended while the worker was still following it (see results below). Once a focal follower ceased following a dance, we classified the action that she took within the next 2 min into one of three categories: exited the hive, moved off the dance floor (out of the view of the camera, but not immediately out of the hive) or remained on the dance floor. We also noted whether focal dance followers followed a second dance at any time during the $2 \mathrm{~min}$ after they stopped following the focal dance.

Finally, we determined relative exit rates for each colony by counting the number of workers that left the hive during the $30 \mathrm{~min}$ after the feeder had been restocked with either 1.0 or $2.0 \mathrm{M}$ sucrose solution. We could not measure recruitment to the feeder because the small size of the greenhouse did not allow us to discriminate between workers who were actively searching for the feeder after following a recruitment dance and those foragers who were exploring the greenhouse and found the feeder by accident. However, we reasoned that differences in exit rates between multiplepatriline and single-patriline colonies may reflect real differences in colony-level recruitment to the feeder.

\section{Statistical analysis}

Two-way ANOVAs (with patriline-diversity treatment and sucrose concentration as factors) were performed on the following data: the number of circuits and tempo of focal dances, the number of dance followers per focal dance, and the number of circuits followed by a focal dancer. For the first three estimates, focal dances were treated as subsamples of each colony replicate. For the latter estimate, the mean number of dance circuits attended by followers $(\leq 3$ followers assessed/dance) was determined for each focal dance, and these mean values were treated as subsamples from each colony replicate. To evaluate the action taken by dance followers in the 2 min after they stopped attending a focal dance, we pooled data across both of the sucrose solutions that were evaluated and determined for each colony the proportion of dance followers that fell into one of the three next-action categories. Proportional data were arcsine-square-root transformed prior to statistical analysis and then compared between treatment groups within each category. We also determined the proportion of dance followers that attended a second dance during the 2 min after they left their focal dance, and these data were compared between treatment groups with $t$ tests. A repeated-measures two-way ANOVA (with patriline-diversity treatment and sucrose concentration as effects, and counts taken repeatedly from each colony over three consecutive 10-min intervals throughout a single trial) was used to determine difference in the mean number of workers that exited colonies throughout the trial. All statistical tests were performed with SAS version 9.1 (SAS Institute Inc., Cary, NC) with an alpha level set at 0.05 . Means are reported with standard errors.

\section{Results}

\section{Focal dances}

A focal dance had significantly more circuits if it was performed by a forager in a multiple-patriline colony compared to a dance that was performed by a forager in a singlepatriline colony (mean $24 \pm 1.7$ and $14 \pm 2.1$ circuits per dance, respectively; $\left.F_{1,28}=14.1, P=0.001\right)$. This is related to a longer on average dance duration in multiplepatriline colonies compared with dances in single-patriline colonies (mean $13.96 \pm 1.09$ and $7.32 \pm 1.31 \mathrm{~s}$, respectively; $\left.F_{1,28}=15.18, \quad P=0.001\right)$, not faster tempos (circuits per second, mean $0.59 \pm 0.03$ and $0.53 \pm 0.04$ circuits per second, respectively; $F_{1,28}=1.41, P=0.25$ ). This result means that differences in the number of circuits attended by dance-following workers in multiple-patriline and single-patriline colonies (see below) reflected a difference in the time spent by workers following dances and not a difference in the circuit-production rate of dancers. For both number of circuits and tempo, neither the effect of sucrose concentration $\left(F_{1,28}=0.0, P=0.96\right.$ and $F_{1,28}=1.1, P=$ $0.3)$ nor its interaction with patriline diversity $\left(F_{1,28}=1.9\right.$, $P=0.18$ and $F_{1,28}=0.04, P=0.85$ ) was significant. Dances in this assay were generally longer as the food reward increased (Mattila and Seeley, 2010). However, when we looked at the subset of dances that fit our focal dance criteria, there was no difference in number of circuits that a dancer produced as the sucrose solution in the feeder increased from 1.0 to $2.0 \mathrm{M}$, probably because we excluded short dances $(<10$ circuits) from our analysis.

We tried to identify up to ten focal dances (all by different foragers) in each colony and concentration combination, but in many cases, fewer than ten focal dances were performed by foragers, even if repeat dancers were 
considered. In total, 75 focal dances were analysed: 43 dances in multiple-patriline colonies and 32 dances in single-patriline colonies. Of these, 18 and 16 of dances, respectively, were produced by foragers who had already performed one focal dance.

\section{Dance followers}

On average, significantly more workers oriented to and followed some part of the first ten circuits of focal dances that were performed in multiple-patriline colonies compared with focal dances that were produced in colonies that were each composed of a single patriline (Fig. $1 \mathrm{a} ; F_{1,28}=$ $14.9, P=0.001)$. Overall, the number of dance followers was $33 \%$ greater per dance in multiple-patriline colonies, which translated into an average of 1-2 more workers attending every 10-circuit segment of a dance compared with similar dance segments in single-patriline colonies (Fig. 1a). The number of workers that followed each focal dance increased slightly, although not significantly, as the concentration of sucrose that was offered in the feeder
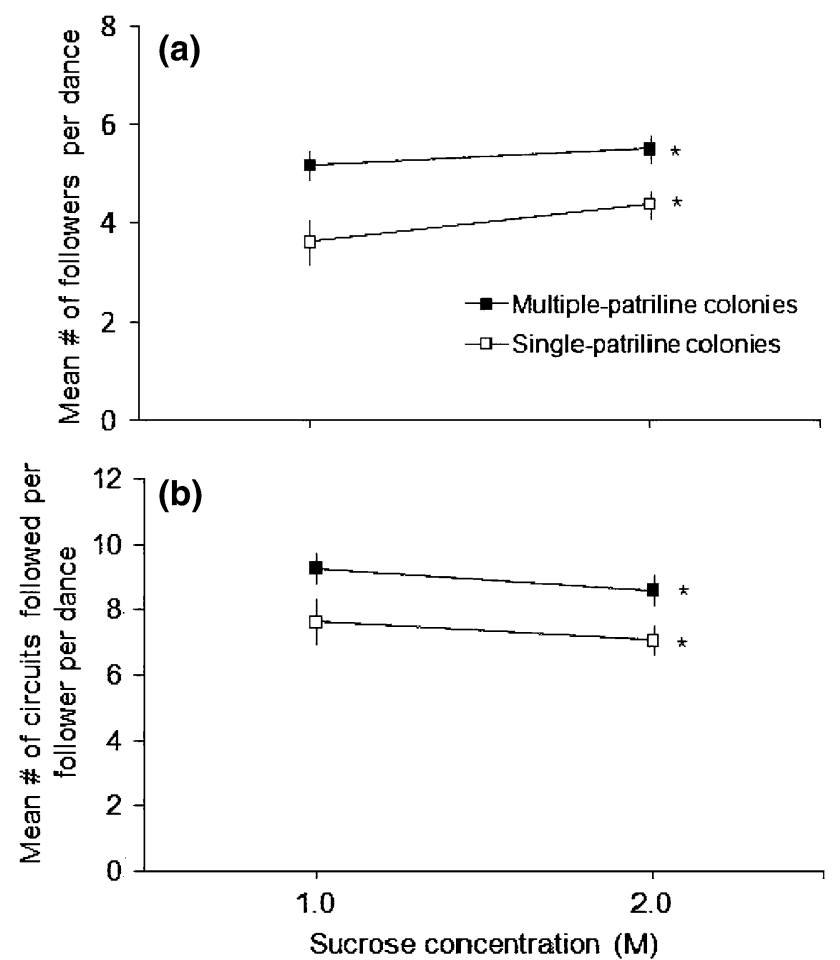

Fig. 1 a Mean number of dance followers $( \pm$ s.e. $)$ that followed at least one circuit of the first ten circuits of a focal dance, and $\mathbf{b}$ mean number of circuits of a focal dance that were followed by a dance follower $( \pm$ s.e. $)$ for dances performed in either multiple-patriline or single-patriline colonies. Dances were produced by foragers who were trained to visit a feeder in a greenhouse that held one of two concentrations of sucrose solution $(1.0$ or $2.0 \mathrm{M})$. Asterisks indicate significant differences between colony types, which were found consistently across sucrose solutions increased (Fig. 1a; $F_{1,28}=3.0, P=0.09$ ), but the nature of this change was not influenced by the patriline diversity of colonies (Fig. 1a; interaction of effects: $F_{1,28}=0.47$, $P=0.50)$.

In addition to an increase in the number of workers that followed each recruitment dance in multiple-patriline colonies, the average dance follower tracked significantly more circuits while attending a focal dance than did the average dance follower in a single-patriline colony (Fig. $1 \mathrm{~b} ; F_{1,28}=$ $9.4, P=0.005)$. Once more, there was neither an effect of sucrose concentration $\left(F_{1,28}=1.4, P=0.24\right)$ nor an interaction between sucrose concentration and patriline-diversity treatments $\left(F_{1,28}=0.01, P=0.93\right)$ on the extent of dance following (Fig. 1b). Over trials with each concentration of sucrose solution, a dance follower in a multiple-patriline colony followed an average of 1.6 more circuits per dance than a dance follower in a single-patriline colony (Fig. 1b). Of the 224 dance followers for whom duration of dance following was assessed, 19 individuals were forced to cut short their dance following because their focal dance ended before they moved away from the dancer. Of these 19 individuals, 14 were from multiple-patriline colonies. Thus, if average following time is artificially lowered by a premature end to dancing in some cases, the underestimate is probably greatest for multiple-patriline colonies.

The patriline diversity of a colony also had a significant effect on the action that a dance follower took after she stopped following a dance (Fig. 2). On average, 2.1 times more dance followers left the hive within 2 min after they

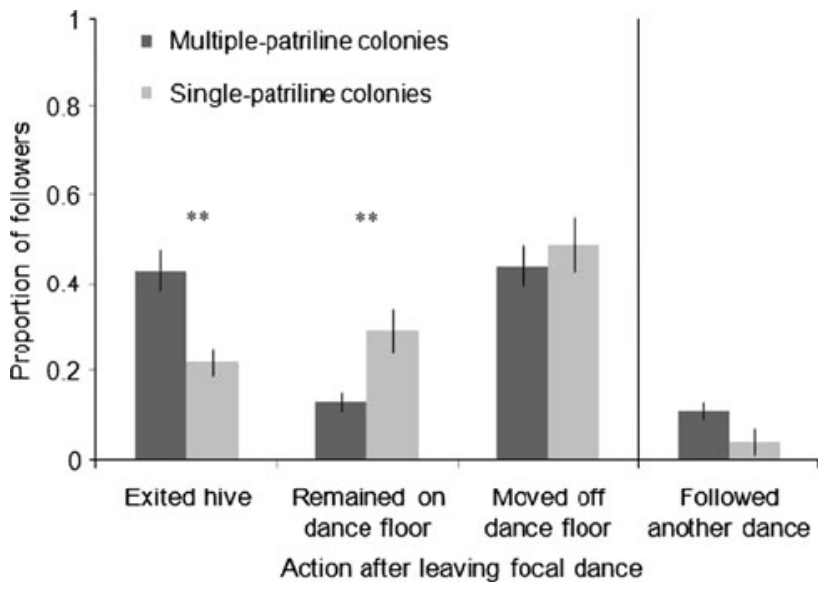

Fig. 2 Mean proportion of dance followers ( \pm s.e.) in multiplepatriline and single-patriline colonies that, within 2 min after they stopped attending their focal dance, either exited the hive, remained on the dance floor, or moved off the dance floor (but not out of the hive), as well as the mean proportion of workers that followed a second dance during this interval (regardless of which of the three actions they took by the end of $2 \mathrm{~min}$ ). Proportions were based on observations of dance followers that attended dances that advertised a feeder that contained 1.0 or 2.0 M sucrose solution (data were pooled across concentrations). Asterisks indicate the actions for which there was a significant difference in proportion between colony types 
stopped attending their focal dance in multiple-patriline colonies compared with workers in single-patriline colonies (Fig. $2 ; t_{4}=3.6, P=0.02$ ). In contrast, dance followers in single-patriline colonies were 2.7 times more likely than their counterparts in multiple-patriline colonies to remain on the dance floor over the same period (Fig. $2 ; t_{4}=-2.8$, $P=0.05)$. There was no difference between multiplepatriline and single-patriline colonies in the proportion of dance followers that walked off the dance floor and moved deeper into the hive (Fig. $2 ; t_{4}=-1.2, P=0.32$ ). Finally, compared with dance followers in single-patriline colonies, there was a strong, yet non-significant, tendency of dance followers from multiple-patriline colonies to follow a second dance within the 2-min time frame after they left their focal dance, regardless of whether followers ultimately left the hive, moved deeper into the hive, or remained on the dance floor (Fig. $2 ; t_{4}=2.5, P=0.07$ ). More than twice (2.8 times) as many dance followers in multiple-patriline colonies attended a second dance compared with followers in single-patriline colonies, but a large amount of variability among colonies in the extent to which workers demonstrated this behaviour prevented discrimination between treatment groups with our sample size.

\section{Relative exit rates from colonies}

A comparison of relative exit rates did not reveal clear differences between colonies based on patriline diversity $\left(F_{1,8}=0.1, P=0.75\right)$ or sucrose solution concentration $\left(F_{1,8}=0.2, P=0.69\right)$. Pooling data from the 1.0 and 2.0 M solutions that were used in the feeder, we found an average of $609 \pm 34.7$ bees left multiple-patriline colonies during the $30 \mathrm{~min}$ that the feeder was stocked with food compared with $644 \pm 90.4$ bees from single-patriline colonies. While we could detect no differences in exiting rates between treatments, we did find an effect of time on the number of workers leaving the hive. Specifically, the exit rate of workers rose over time while food was available in the feeder (Fig. $3 ; F_{2,16}=67.3, P<0.0001$ ).

\section{Discussion}

This study demonstrates that a honey bee colony with multiple patrilines makes greater use of recruitment-signal communication than a colony that lacks such genetic diversity. Communication is enhanced through two important mechanisms and complementary perspectives when a colony has numerous patrilines: first, by the production of more signals by each sender (Mattila et al., 2008; Mattila and Seeley, 2010) and, second, by heightened exposure of receivers to those signals (shown here). Signal receipt was increased because dances that advertised a "nectar source"

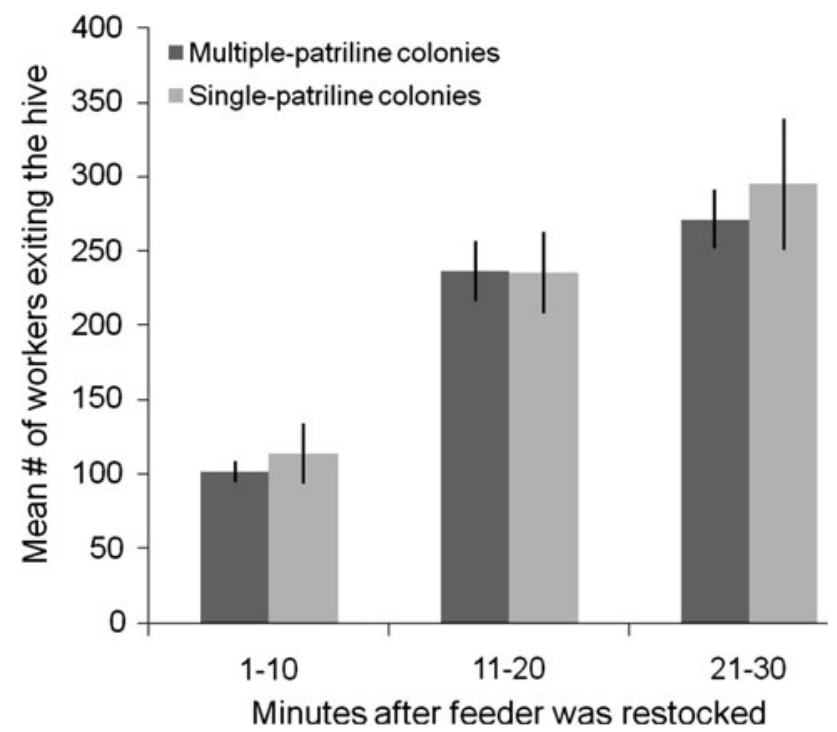

Fig. 3 Mean number of workers ( \pm s.e.) that left the hive during the 30 -min period when the feeder was stocked with either 1.0 or $2.0 \mathrm{M}$ sucrose solution (divided into three 10-min intervals). Exit rates were monitored for multiple-patriline and single-patriline colonies; patriline diversity did not have a significant effect on exit rates. Data were pooled across sucrose solutions

(i.e. a feeder stocked with sucrose solution) in multiplepatriline colonies generated larger audiences of more attentive dance followers than dances in single-patriline colonies. On average, in multiple-patriline colonies compared with single-patriline colonies, $33 \%$ more workers followed each focal dance and for almost 2 more circuits per worker. In addition to a greater number of workers following each dance and for a longer time on average, dance followers from multiple-patriline colonies were 2.7 times more likely to leave the hive within 2 min after they stopped attending a focal dance compared with their counterparts in single-patriline colonies. Conversely, a significantly greater proportion of dance followers from single-patriline colonies remained on the dance floor after they stopped following a dance, perhaps having become disengaged from the recruitment process, as suggested by their lower tendency to seek out subsequent dances. That such strong differences were found between colony types with a modest sample size (a necessary trade of colony number for detailed behavioural observations) is compelling evidence that these differences are real. Furthermore, it reinforces the trend that single-patriline honey bee colonies consistently underperform relative to multiple-patriline colonies (Fuchs and Schade, 1994; Jones et al., 2004; Mattila and Seeley, 2007, 2010; Mattila et al., 2008; Oldroyd et al., 1992), rather than showing similar mean performance with a relative increase in variation around that mean.

For reasons that were not made clear by this study, relative exit rates from the colony during the $30 \mathrm{~min}$ that the 
feeder was open did not reflect this greater tendency of workers in multiple-patriline colonies to leave the hive after following a dance. These results were surprising, given that concurrent increases in waggle dancing and foraging rates have been found in multiple-patriline colonies relative to single-patriline colonies in other contexts (Mattila and Seeley, 2007; Mattila et al., 2008). These conflicting findings may reflect our inability to disentangle in a greenhouseforaging assay counts of workers who were exiting their hive in search of the feeder from those workers who were leaving for other reasons (e.g., searching for the water source, orientating to the entrance and greenhouse, cleansing flights). Further study is needed to determine whether potential recruits in multiple-patriline colonies are not only more receptive to dance signals, but are also more successful after they leave the hive in the use of the information that they receive-that is, whether they are more likely to find a food source after following a dance that advertises it because they have more information about it. Such an experiment should be executed in a natural foraging environment with a greater distance between the feeder and the hive so that the extent to which extra information helps dance followers to locate a food source can be determined definitively.

It is important to emphasize that we found increases in dance-following activity on a per-dance-circuit basis as foragers from multiple-patriline and single-patriline colonies visited a strictly controlled, singular resource. Therefore, the greater number of bees attending dances in multiple-patriline colonies is not only the result of greater signal production by dancing foragers in these colonies (i.e. relatively longer focal dances; see also Mattila and Seeley, 2010), but also a reflection of increased exposure of potential recruits to each dance circuit. This colony-level finding extends our understanding of the reasons why, in honey bee colonies, work force productivity and foraging effort are enhanced when colonies have a high degree of genetic diversity (Mattila and Seeley, 2007; Mattila et al., 2008). Such boosts in the responsiveness of workers to recruitment signals may explain a similar report of increased foraging productivity in genetically diverse ant colonies with polyandrous queens (Wiernasz et al., 2008).

Differences in the dance-following activity of workers between multiple-patriline and single-patriline colonies may be explained by two hypotheses that are not mutually exclusive. First, it may be the case that dances performed by foragers in multiple-patriline colonies are more attractive to their nest mates, prompting a greater number of workers to orient and remain attentive to them. Our analysis of focal dancers did not indicate that dances performed in genetically diverse colonies conveyed more "excitement" or "enthusiasm" [at least, based on their tempo (Seeley et al., 2000)] than those performed in genetically uniform col- onies, although they could have been more appealing to potential recruits based on parameters that we did not evaluate, such as the amplitude of the brief waggle movements, the release by dancers of pheromones that modulate nest mate behaviour (Thom et al., 2007), or a overall levels of activity on the dance floor. The fact that the focal dances were longer on average in multiple-patriline colonies may reflect an aspect of attractiveness that was not captured by our study. The second hypothesis considers the nature of the dance followers themselves. It is possible that dance-following activity was enhanced in some proportion of the worker population in multiple-patriline colonies for one or a number of the following reasons: because some workers had (1) a genetic propensity to participate in dance following (Arnold et al., 2002), (2) generally lower thresholds for initiating a dance-following response to dance-signal stimuli (Robinson and Page, 1988), (3) faster response times to dances-which are often short-once they began, (4) greater attention spans, which could result in greater time spent attending a dance, (5) differences in the probability of response once thresholds were exceeded (Weidenmüller, 2004), or (6) a strong inclination to advertise a nectar resource over other types of forage, such as pollen (Hunt et al., 1995; Oldroyd et al., 1991). Any combination of these trait differences would generate a boost in the dance-following activity of workers and increase the size of the audience that heeds the signals that are produced in multiple-patriline colonies. None of these hypotheses can be ruled out by this study, and we believe that it is likely that several are reasons why communication is enhanced in colonies with a high degree of patriline diversity.

Above all, an interesting question that remains unanswered is the extent to which patrilines of workers differentially participated as audience members in recruitment signalling. Here, we have demonstrated substantial differences in colony-level exchange of recruitment signals in multiple- and single-patriline colonies; however, we were not able to determine the role that patriline membership played in forming the response of a colony's forager work force to recruitment dances when numerous patrilines were present in a colony, primarily because destructively sampling focal followers would have interfered with our behavioural observations. This line of investigation is important to pursue given that, within the same experimental setup, small subsets of patrilines were responsible for producing a majority of the dance signals in these colonies (Mattila and Seeley, 2010).

Foragers who successfully locate a food source that is advertised by a waggle dance need to follow a mean of at least eight waggle runs of a dance to obtain sufficient information about the location of that resource (Judd, 1995). The same information about distance and direction that is encoded in waggle dances for faraway food sites is also 
found in so-called "round dances" (i.e. dance signals that contain brief waggle phases) that broadcast the location of resources that are near the colony (Kirchner et al., 1988; Jensen et al., 1997; Gardner et al., 2007). It is not clear whether successful recruits need to follow more or less than eight circuits of a recruiting "round" waggle to find nearby sites with the same degree of success, but it is interesting that the average number of circuits followed by dance followers in this study hovers around this 8-circuit mark (Fig. 1b), the threshold number of informative waggle signals shown by Judd (1995) to promote successful food-site discovery by dance-following recruits. Furthermore, calculated across concentrations, the average number of circuits followed in single-patriline colonies was less than eight per follower. Although dance-following workers in multiple-patriline colonies followed an average of only 1.6 more circuits per dance compared with workers in single-patriline colonies, this difference may have noteworthy consequences if it creates large differences in recruitment success simply because more workers in multiple-patriline colonies are exposed to a threshold number of dance signals, either a number that prompts them to exit the nest (as seen here) or one that allows sufficient time for recruits to glean enough information to successfully locate the resource. Had dance followers already known the location of the feeder because they had visited it recently, perhaps the number of circuits that they followed may be of lesser importance if attendance at a dance only jogged followers' memories through reactivation. However, the design of our study greatly limited the experience that dance followers had with the feeder and, thus, we expected that workers who were stimulated to locate the resource would follow sufficient numbers of dances signals to allow them to learn adequate information about the feeder before leaving the hive. Based on such a scenario, we infer that workers from multiple-patriline colonies are more motivated to learn about the food source than workers from single-patriline colonies. Furthermore, the tendency exhibited by workers in multiple-patriline to follow a second dance (for the feeder) before exiting the hive may also reflect increased motivation to learn about food sources in general, or our feeder specifically, relative to dance followers in single-patriline colonies.

It is becoming abundantly clear that the execution of a large-scale, self-organized foraging effort in genetically diverse honey bee colonies is enhanced both by the production of more signals by waggle-dancing foragers and by increased responsiveness of the audience of workers for whom the dance signals are intended. By raising the activity of both signal producers and receivers, multiple mating expedites the transfer among nest mates of information about available resources. The advantage of such amplification of communication is also observed in simultaneous group departures that are characteristic of gorillas (Stewart and Harcourt, 1994) and flocks of whooper swans (Black, 1988). Initially, a few individuals make their intention to leave known through the production of signals, which are imitated by other members of the group who are similarly motivated to leave. For both gorillas and whooper swans, a threshold level of vocalizations or body movements must be produced by the collective before group action is taken. Hence, communication is enhanced by positive feedback because increased signalling draws the attention of more group members, who in turn become signallers. A similar positive feedback is probably at work in honey bee colonies: longer and more frequent dance signals, coupled with a more receptive audience of dance followers, likely begets even more dancing as these motivated audience members search for and discover advertised resources and, presumably, become signal producers (with some probability) upon return to their hive. Beyond the influence of genetic diversity on recruitment signalling in honey bee colonies, this study highlights the need to examine not only the perspective of signal producers, but also the perspective of signal receivers when evaluating the efficacy of communication in animal systems. After all, it is the action, or the lack thereof, taken by a signal producer's audience that determines the success of the effort to communicate.

Acknowledgments We thank Morgan Carr-Markell for help with data collection. We are grateful to the funding agencies that supported this research: Federal Work-Study Program (M.B.G.), Natural Sciences and Engineering Research Council of Canada (Postdoctoral Fellowship to H.R.M.) and two grants from the National Research Initiative of the US Department of Agriculture Cooperative State Research, Education and Extension Service (no. 2003-35302-13387 and no. 2007-35302-18174 to T.D.S.). We also thank anonymous reviewers for helpful suggestions that greatly improved the manuscript.

Open Access This article is distributed under the terms of the Creative Commons Attribution Noncommercial License which permits any noncommercial use, distribution, and reproduction in any medium, provided the original author(s) and source are credited.

\section{References}

Arnold G., Quenet B., Papin C., Masson C. and Kirchner W.H. 2002. Intra-colonial variability in the dance communication in honeybees (Apis mellifera). Ethology 108: 751-761

Baer B. and Schmid-Hempel P. 2001. Unexpected consequences of polyandry for parasitism and fitness in the bumblebee, Bombus terrestris. Evolution 55: 1639-1643

Beekman M., Peeters C. and O'Riain M.J. 2006. Developmental divergence: neglected variable in understanding the evolution of reproductive skew in social animals. Behav. Ecol. 17: 622-627

Black J.M. 1988. Preflight signalling in swans: a mechanism for group cohesion and flock formation. Ethology 78: 143-157

Boomsma J.J. 2009. Lifetime monogamy and the evolution of eusociality. Phil. Trans. R. Soc. B 364: 3191-3207

Brown M.J.F. 2003. The evolution of female multiple mating in social Hymenoptera. Evolution 57: 2067-2081 
Cole B.J. and Wiernasz D.C. 1999. The selective advantage of low relatedness. Science 285: 891-893

Crozier R.H. and Fjerdingstad E.J. 2001. Polyandry in social Hymenoptera-disunity in diversity? Ann. Zool. Fenn. 38: 267-285

Crozier R.H. and Page R.E. 1985. On being the right size: male contributions and multiple mating in social Hymenoptera. Behav. Ecol. Sociobiol. 18: 105-115

Foster K.R. and Ratnieks F.L.W. 2001. Paternity, reproduction and conflict in vespine wasps: a model system for testing kin selection predictions. Behav. Ecol. Sociobiol. 50: 1-8

Fuchs S. and Schade V. 1994. Lower performance in honeybee colonies of uniform paternity. Apidologie 25: 155-168

Gardner K.E., Seeley T.D., and Calderone N.W. 2007. Do honeybees have two discrete dances to advertise food sources? Anim. Behav. 75: $1291-1300$

Goodisman M.A.D, Kovacs J.L. and Hoffman E.A. 2007. The significance of multiple mating in the social wasp Vespula maculifrons. Evolution 61: 2260-2267

Hamilton W.D. 1964. The genetical evolution of social behavior, I and II. J. Theor. Biol. 7: 1-52

Hughes W.O.H., Oldroyd B.P., Beekman M. and Ratnieks F.L.W. 2008a. Ancestral monogamy shows kin selection is key to the evolution of eusociality. Science 320: 1213-1216

Hughes W.O.H., Ratnieks F.L.W. and Oldroyd B.P. 2008b. Multiple paternity or multiple queens: two routes to greater intracolonial genetic diversity in the eusocial Hymenoptera. J. Evol. Biol. 21: 1090-1095

Hunt G.J., Page R.E. Jr, Fondrk M.K. and Dullum C.J. 1995. Major quantitative trait loci affecting honey bee foraging behavior. Genetics 141: 1537-1545

Jensen I.L., Michelsen A. and Lindauer M. 1997. On the directional indications in the round dances of honeybees. Naturwissenschaften 84: 452-454

Jones J.C., Myerscough M.R., Graham S. and Oldroyd B.P. 2004. Honey bee nest thermoregulation: diversity promotes stability. Science 305: 402-404

Judd T.M. 1995. The waggle dance of the honey bee: which bees following a dancer successfully acquire the information. J. Insect Behav. 8: $343-354$

Kirchner W.H., Lindauer M. and Michelsen A. 1988. Honeybee dance communication: acoustical indication of direction in round dances. Naturwissenschaften 75: 629-630

Kronauer D.J.C., Berghoff S.M., Powell S., Denny A.J., Edwards K.J., Franks N.R. and Boomsma J.J. 2006. A reassessment of the mating system characteristics of the army ant Eciton burchellii. Naturwissenschaften 93: 402-406

Kronauer D.J.C, Schöning C., Pedersen J.S., Boomsma J.J. and Gadau J. 2004. Extreme queen-mating frequency and colony fission in African army ants. Mol. Ecol. 13: 2381-2388

Mattila H.R., Burke K.M. and Seeley T.D. 2008. Genetic diversity within honeybee colonies increases signal production by waggledancing foragers. Proc. R. Soc. B 275: 809-816

Mattila H.R. and Seeley T.D. 2010. Promiscuous honeybee queens generate colonies with a critical minority of waggle-dancing foragers. Behav. Ecol. Sociobiol. 64: 875-889

Mattila H.R. and Seeley T.D. 2007. Genetic diversity in honey bee colonies enhances productivity and fitness. Science 317: 362-364

Moritz R.F.A., Kryger P. and Allsopp M.H. 1996. Competition for royalty in bees. Nature 384: 31

Oldroyd B.P. and Fewell J.H. 2008. Large fitness benefits from polyandry in the honey bee, Apis mellifera. Trends Ecol. Evol. 23: 59-60

Oldroyd B.P., Rinderer T.E. and Buco S.M. 1991. Honey bees dance with their supersisters. Anim. Behav. 42: 121-129

Oldroyd B.P., Rinderer T.E., Harbo J.R. and Buco S.M. 1992. Effects of genetic diversity on honey bee (Apis mellifera) (Hymenoptera: Apidae) colony performance. Annls Entomol. Soc. 85: 335-343
Oldroyd B.P. and Wongsiri S. 2006. Asian Honey Bees: Biology, Conservation and Human Interactions. Harvard University Press. pp 118-145

Page R.E. 1980. The evolution of multiple mating behavior by honey bee queens (Apis mellifera L.). Genetics 96: 263-273

Palmer K.A. and Oldroyd B.P. 2003. Evidence for intra-colonial genetic variance in resistance to American foulbrood of honey bees (Apis mellifera): further support for the parasite/pathogen hypothesis for the evolution of polyandry. Naturwissenschaften 90: $265-268$

Palmer K.A. and Oldroyd B.P. 2000. Evolution of multiple mating in the genus Apis. Apidologie 31: 235-248

Robinson G.E. and Page Jr R.E. 1988. Genetic determination of guarding and undertaking in honey-bee colonies. Nature 333: 356-358

Seeley T.D. 1995. The Wisdom of the Hive: the Social Physiology of Honey Bee Colonies. Harvard University Press, Cambridge Massachusetts. pp 35-44

Seeley T.D., Mikheyev A.S. and Pagano G.J. 2000. Dancing bees tune both duration and rate of waggle-run production in relation to food-source profitability. J. Comp. Physiol. A 186: 813-819

Seeley T.D. and Tarpy D.R. 2007. Queen promiscuity lowers disease within honeybee colonies. Proc. R. Soc. B 274: 67-72

Shaskolsky D.V. 1976. Polyandry: defending the colony against a great number of lethal eggs. In: Apimondia Symposium on Bee Biology, Bucharest. pp 67-71

Sherman P.W., Seeley T.D. and Reeve H.K. 1988. Parasites, pathogens and polyandry in social Hymenoptera. Am. Nat. 131: 602-610

Stewart K.J. and Harcourt A.H. 1994. Gorillas' vocalizations during rest periods: signals of impending departure. Behaviour 130: $29-40$

Strassmann J. 2001. The rarity of multiple mating by females in the social Hymenoptera. Insect. Soc. 48: 1-13

Tarpy D.R., Nielsen R. and Nielsen D.I. 2004. A scientific note on the revised estimates of effective paternity frequency in Apis. Insect. Soc. 51: 203-204

Tarpy D.R. and Page Jr R.E. 2002. Sex determination and the evolution of polyandry in honey bees (Apis mellifera). Behav. Ecol. Sociobiol. 52: 143-150

Tarpy D.R. and Seeley T.D. 2006. Lower disease infections in honeybee (Apis mellifera) colonies headed by polyandrous vs monandrous queens. Naturwissenschaften 93: 195-199

Thom C., Gilley D.C., Hooper J. and Esch H.E. 2007. The scent of the waggle dance. PLoS Biology 5: 1862-1867

Villesen P., Murakami T., Schultz T.R. and Boomsma J.J. 2002. Identifying the transition between single and multiple mating of queens in fungus growing ants. Proc. $R$. Soc. B 269: 1541-1548

von Frisch K. 1967. The Dance Language and Orientation of Bees. Harvard University Press, Cambridge Massachusetts. 592 pp

Wattanachaiyingcharoen W., Oldroyd B.P., Wongsiri S., Palmer K. and Paar R. 2003. A scientific note on the mating frequency of Apis dorsata. Apidologie 34: 85-86

Weidenmüller A. 2004. The control of nest climate in bumblebee (Bombus terrestris) colonies: interindividual variability and self reinforcement in fanning response. Behav. Ecol. 15: 120-128

Wiernasz D.C., Hines J., Parker D.G. and Cole B.J. 2008. Mating for variety increases foraging activity in the harvester ant, Pogonomyrmex occidentalis. Mol. Ecol. 17: 1137-1144

Wiernasz D.C., Perroni C.L. and Cole B.J. 2004. Polyandry and fitness in the western harvester ant, Pogonomyrmex occidentalis. Mol. Ecol. 13: 1601-1606

Wilson E.O. 1971. The Insect Societies. Belknap Press, Harvard University, Cambridge Massachusetts. 548 pp

Wray M.K., Klein B.A., Mattila H.R. and Seeley T.D. 2008. Honeybees do not reject dances for 'implausible' locations: reconsidering the evidence for cognitive maps in insects. Anim. Behav. 76: 261-269 